\title{
Desempenho produtivo e composição do leite de vacas da raça holandesa no final da lactação, manejadas em pastagem e suplementadas com diferentes níveis de concentrado
}

\author{
Holstein cows productive performance and milk composition \\ in late lactating, management in pasture supplemented \\ with different levels of concentrate
}

\author{
Marcelo Falci Mota, ${ }^{*}$ Duarte Vilela, ${ }^{* *}$ Geraldo Tadeu dos Santos, ${ }^{* * *}$ Ana Cristina Wyllie Elyas, ${ }^{* \star *}$ \\ Fernando César Ferraz Lopes, ${ }^{\star *}$ Rui da Silva Verneque, ${ }^{* *}$ Adalgiza Pinto Neto*
}

\begin{abstract}
Resumo
Foram utilizadas 36 vacas da raça Holandesa na fase final de lactação em um delineamento com parcelas sub-subdivididas, em pastejo de Coastcross, com o objetivo de se avaliar diferentes quantidades de suplementação: três e seis quilos de concentrado, sobre o desempenho animal (produção e composição do leite, peso e condição corporal). O Coastcross manejado em pastejo intermitente no período de verão, com lotação de cinco unidades animal por hectare apresentou em média 11,7\% de PB; $70,2 \%$ de FDN; $35,2 \%$ de FDA e $63,7 \%$ de digestibilidade in vitro da matéria seca. A maior ingestão de concentrado pelas vacas que receberam seis quilos de concentrado não afetou $(P>0,05)$ a produção de leite, os teores de proteína, gordura, lactose e sólidos totais do leite produzido. No entanto, o escore da condição corporal (ECC) e a contagem de células somáticas (CCS) aumentaram com a maior suplementação de concentrado. Concluiu-se então que a suplementação de vacas holandesas no terço final de lactação mantidas em pastejo de Coastcross sp, com três e seis quilos de concentrado, não influenciou o peso corporal, a produção e a composição do leite (gordura, proteína, lactose e sólidos totais). No entanto, a maior suplementação influenciou o ECC e a CCS.
\end{abstract}

Palavras-chave: vacas holandesas, Coastcross, suplementação, produção de leite, composição do leite.

\begin{abstract}
Thirty-six late lactating Holstein cows in a split-split-plot design model in a Coast-cross pasture were used in order to assess different amounts of supplement: three and six kilos of concentrate mixture under the animal performance (milk production and composition, body weight and body condition). The coast-cross managed in intermittent grazing in the summer, with a stocking rate of 5 animal/ hectare presented an average of $11.7 \%$ of CP; $70.2 \%$ of NDF; $35.2 \%$ of ADF, and $63.7 \%$ of in vitro dry matter digestibility. Higher ingestion of concentrate mixture by the cows which received six kilos of concentrate mixture did not affect milk production $(\mathrm{P}<0.05)$, the protein content, lactose, and of the total solids in the milk produced. However, the body conditions score (BCS) and the somatic cell count (SCC) increase as a result of the higher supplement of concentrate mixture. It was thus concluded that supplementing late lactating Holstein cows grazing on coast-cross pasture with three or six kilos of concentrate mixture did not influence their body weight, production, and milk composition (fat, protein, lactose, and total solids). However, higher supplementation influenced both BCS and SCC.
\end{abstract}

Keywords: Holstein cows, coast-cross, supplementation, milk production, milk composition.

\section{Introdução}

Com aproximadamente $80 \%$ do território concentrado na faixa tropical, o Brasil apresenta inquestionável aptidão para produção de leite em sistemas de criação de bovinos que se baseiam em pastagens.

As gramíneas predominantes no país são do tipo $C_{4}$, com características de alta eficiência fotossintética e elevada taxa de crescimento. As forrageiras do gênero Cynodon, (cv) Coastcross apresentam alta produção de matéria seca e adequado valor nutritivo, que podem proporcionar alta taxa de lotação e produção de leite por hectare.

Em alguns sistemas de produção a pasto faz-se necessário o uso de complementos alimentares para que seja mantido desempenho animal, em produção de leite e/ou em ganho de peso, em níveis aceitáveis (Reis e Antunes, 1999),

\footnotetext{
* Professores do Curso de Medicina Veterinária - UNIPAR. Umuarama-PR.

Endereço para correspondência: Rua Paulo Pedrosa de Alencar, 4491 - Zona 01 - CEP: 87501-270 - Umuarama-PR.

Fones: (44) 3055-2247 / (44) 9914-6748 / (44) 3621-2550 HV - E. mail: mfalcimota@yahoo.com.br; marcelofalci@unipar.br

** Pesquisador. EMBRAPA - Gado de Leite.

*** Professor. Pesquisador CNPq. Departamento de Zootecnia - UEM. Maringá-PR.

**** Doutoranda em Zootecnia - UFLA. Lavras-MG.
} 
principalmente quando se avaliam animais selecionados geneticamente para essas características, como vacas de alta produção leiteira.

A quantidade e qualidade do volumoso e do concentrado consumido pelos animais influenciam a quantidade e a composição do leite produzido. Os componentes do leite podem ser alterados por fatores genéticos e não-genéticos. Antes de se avaliar as características genéticas que determinam os componentes do leite, é fundamental que se conheça a influência e importância dos fatores não-genéticos para esses componentes, como, por exemplo, o manejo nutricional (Teixeira et al. 2003).

A alimentação da vaca leiteira influencia a composição do leite produzido. Sendo assim, a análise dos componentes do leite é uma importante ferramenta para a avaliação nutricional da dieta desse animal, que pode revelar informações sobre a eficiência de utilização dos nutrientes e sobre a saúde da vaca produtora. Os dados obtidos através dessa análise contribuem para o adequado balanceamento da dieta, resultando em melhor desempenho do animal e/ou redução dos custos de produção (Gustafsson e Palmquist, 1993).

O objetivo deste estudo foi avaliar a produção e a composição do leite, o peso e a condição corporal, de vacas da raça Holandesa no terço final da lactação, em pastejo intermitente de Cynodon dactylon cv. Coastcross, suplementadas com três e seis quilos de concentrado por dia.

\section{Material e métodos}

Esse estudo foi conduzido durante o período de 13 de janeiro a 23 de março de 2003, na EMBRAPA - Gado de Leite, no Campo Experimental de Coronel Pacheco, em Coronel Pacheco, Minas Gerais, que se localiza na Zona da Mata a 426 metros de altitude, $21^{\circ} 55^{\prime} 55^{\prime \prime}$ de latitude Sul e $43^{\circ} 16^{\prime} 15^{\prime \prime}$ de longitude Oeste. O tipo climático do Campo Experimental da EMBRAPA é CWA, segundo a classificação de Köppen, apresentando verões quentes e chuvosos, com invernos secos e frios.

Os dados médios de temperatura, umidade relativa do ar, insolação e precipitação pluviométrica, observados durante 0 período experimental, encontram-se relatados na Tabela 1.
Utilizaram-se como animais experimentais 36 vacas da raça Holandesa, HPO (pura de origem) ou HPC (pura por cruza), no terço final da lactação (média: $221 \pm 112$ dias de lactação), de diferentes idades, partos e peso corporal.

Os animais experimentais foram mantidos em lotação intermitente de Cynodon dactylon cv Coastcross, recebendo sal mineral e água ad libitum, e diferentes suplementações de concentrado.

Esses animais foram divididos em dois grupos experimentais, com duas repetições (blocos) cada. Os animais do grupo 1 (SU1) receberam suplementação de três quilos de concentrado por dia, e se encontravam em média com $207 \pm$ 107 dias de lactação, enquanto os animais do grupo 2 (SU2) com $233 \pm 119$ dias de lactação receberam seis quilos de concentrado/dia. O concentrado foi fornecido em partes iguais, duas vezes ao dia, durante a ordenha, realizada as sete e 15 horas, e sua composição apresenta-se descrita na Tabela 2.

Tabela 2: Proporção dos ingredientes das dietas fornecidas aos animais experimentais em quilo da matéria seca (Kg MS). Animais do Grupo SU1 receberam três quilos de concentrado e os do Grupo SU2, seis quilos

\begin{tabular}{llcc}
\hline Tipo de Dieta & Ingredientes (Kg MS) & \multicolumn{2}{c}{ Grupos Experimentais } \\
\cline { 3 - 4 } & & SU1 & SU2 \\
\hline Volumoso & Coastcross (Kg MS/ha) & 6.725 & 6.040 \\
\hline \multirow{2}{*}{ Concentrado } & Soja integral tostada & 0,935 & 1,869 \\
& Milho moído & 1,655 & 3,34 \\
& Sal Mineral & 0,0534 & 0,106 \\
& Calcário calcítico & 0,026 & 0,053 \\
\hline
\end{tabular}

*Composição do sal mineral: $90 \mathrm{~g}$ cálcio, $70 \mathrm{~g}$ fósforo, $80 \mathrm{~g}$ magnésio, $700 \mathrm{mg}$ cobre, $5400 \mathrm{mg}$ zinco, $50 \mathrm{~g}$ cobalto, $180 \mathrm{~g}$ iodo, $40 \mathrm{mg}$ selênio, $20 \mathrm{~g}$ enxofre, $200 \mathrm{~g}$ sódio e $500 \mathrm{mg}$ manganês.

Com intuito de se avaliar a quantidade e qualidade da forrageira disponível e determinar os nutrientes ingeridos pelos animais experimentais, realizaram-se coletas de amostras da forragem em cada piquete em seu respectivo período experimental, por meio de cortes da forragem a 15 $\mathrm{cm}$ do solo, em uma área útil de um metro quadrado, que

Tabela 1: Valores médios da temperatura $\left({ }^{\circ} \mathrm{C}\right)$, umidade relativa do ar (UR), insolação e precipitação pluviométrica $\left(\mathrm{mm}^{3}\right)$, ocorridos durante o período experimental no Campo Experimental da EMBRAPA, em Coronel Pacheco-MG

\begin{tabular}{|c|c|c|c|c|c|c|c|c|c|c|c|}
\hline \multirow[b]{2}{*}{ DATA } & \multicolumn{5}{|c|}{ TEMPERATURA $\left({ }^{\circ} \mathrm{C}\right)$} & \multicolumn{3}{|c|}{ UR (\%) } & \multirow[b]{2}{*}{$\begin{array}{l}\text { INSOLAÇÃOO } \\
\text { (h) }\end{array}$} & \multicolumn{2}{|c|}{ PRECIPITAÇÃO } \\
\hline & 9h & $15 \mathrm{~h}$ & $21 \mathrm{~h}$ & Máx. & Mín. & $9 \mathrm{~h}$ & $15 \mathrm{~h}$ & $21 \mathrm{~h}$ & & $\mathrm{~mm}^{3} / 10$ dias & $\mathrm{mm}^{3} / \mathrm{mês}$ \\
\hline 10/01/03 & 25,3 & 28,8 & 23 & 30,6 & 20,5 & 82 & 70 & 92 & 36,4 & 75,6 & \\
\hline 20/01/03 & 24,3 & 27,7 & 22,8 & 29,3 & 20,3 & 84 & 73 & 94 & 33,4 & 177,7 & \\
\hline $31 / 01 / 03$ & 25,1 & 29,7 & 23,3 & 30,7 & 20,5 & 81 & 59 & 89 & 59,3 & 98,1 & 351,4 \\
\hline $10 / 02 / 03$ & 25,9 & 31,3 & 23,1 & 32,1 & 19,0 & 74 & 51 & 84 & 114,1 & 4,4 & \\
\hline $20 / 02 / 03$ & 25,9 & 30,8 & 22,2 & 32,3 & 18,6 & 75 & 52 & 87 & 82,6 & 112,4 & \\
\hline $28 / 02 / 03$ & 26,6 & 32,1 & 22,8 & 33,3 & 19,1 & 71 & 47 & 85 & 92,9 & 0 & 116,8 \\
\hline $10 / 03 / 03$ & 25,5 & 31,5 & 23,2 & 32,6 & 18,8 & 75 & 50 & 81 & 78,3 & 16,4 & \\
\hline 20/03/03 & 23,9 & 28,2 & 22,8 & 29,7 & 20,5 & 86 & 66 & 90 & 37,4 & 227 & \\
\hline $31 / 03 / 03$ & 23,4 & 27,5 & 21,9 & 28,5 & 18,8 & 80 & 62 & 87 & 60,3 & 25,1 & 268,5 \\
\hline MEDIA & 25,1 & 29,73 & 22,78 & 31,01 & 19,56 & 78,66 & 58,88 & 87,6 & 66,0 & 8,18 & 245,5 \\
\hline
\end{tabular}

Fonte: Estação meteorológica de CECP: Embrapa Gado de Leite, Coronel Pacheco-MG.

Legenda: UR: umidade relativa; Máx.: Máxima; Mín.: Mínima. 
foram identificadas, pesadas, embaladas em sacos plásticos e congeladas a $-10^{\circ} \mathrm{C}$.

Após o término do período experimental, as amostras foram pré-secadas em estufa de ventilação forçada $\left(65^{\circ} \mathrm{C}\right)$, durante 72 horas, moídas em moinho de facas tipo Willey (peneira com perfurações de $1 \mathrm{~mm}$ ), e analisadas quanto ao teor de matéria seca a 105C por 72 horas, e de proteína bruta (PB), pelo método Kjeldahl (SILVA, 1998). As análises para fibra em detergente neutro (FDN) e fibra em detergente ácido (FDA) foram realizadas segundo Van Soest et al. (1991).

Para as análises da composição do leite foram coletadas amostras individuais mensais, em recipiente com 2-bromo-2-nitropropano-1,3-diol $\left(\right.$ Bronopol $^{\circledR}$ ) como conservante, durante todo o período experimental, de todas as vacas, onde as mesmas foram avaliadas no Laboratório da Qualidade do Leite, Embrapa - CNPGL, em Juiz de Fora - MG. A composição do leite foi avaliada quanto ao teor de proteína, lactose, gordura, extrato seco total (EST) e contagem de células somáticas (CCS).

Avaliou-se diariamente a produção de leite e o escore da condição corporal (Edmonson et al., 1989), e também o peso dos animais experimentais. Trabalhouse com o leite corrigido com o valor de gordura para $4 \%$, utilizando a seguinte equação: $C G L 4 \%=(0,4+$ $0,15 \times$ percentagem da gordura do leite) $\times \mathrm{kg}$ de leite, onde CGL significa correção da gordura do leite.

O estudo da produção diária de leite, condição corporal e peso das vacas seguiram um delineamento inteiramente casualizado com parcela sub-subdividida, onde na parcela se encontravam os tratamentos (SU1 e SU2) e na subparcela as repetições ou os blocos (1, 2, 3 e 4) nas três fases do período experimental (janeiro, fevereiro e março).

As médias geradas pelo estudo de produção diária de leite, constituintes do leite, condição corporal e peso vivo das vacas foram ajustadas no seguinte modelo estatístico: $Y_{i \mathrm{ikl}}=\mathrm{m}+\mathrm{T}_{\mathrm{i}}+$ $e_{i j}+P_{k}+T P_{i k}+d_{i j k}+f_{i j k l}$, em que: $Y_{i j k l}=$ observação na vaca $l$, no período $k$, no sistema $j$ e no tratamento $i ; m=$ média geral; $T_{i}$ = efeito do tratamento $i ; e_{i j}=$ resíduo a (da parcela), ou efeito do sistema $j$ dentro do tratamento $i ; P_{k}=$ efeito do período $k$; $T P_{i k}=$ efeito da interação do tratamento $i$ com o período $k ; d_{i j k}$ = resíduo b (da subparcela), ou efeito da interação do tratamento $i$ com o sistema $j$ e com o período $k$; $f_{i j k l}=$ resíduo c (da sub-subparcela).

Os dados médios foram testados através do procedimento GLM, utilizando-se o pacote estatístico SAS (1996).

\section{Resultados e discussão}

A gramínea Cynodon dactylon cv Coastcross, apresentou em média $11,70 \%$ de PB, $70,20 \%$ de FDN, 35,20\% de FDA e $63,7 \%$ de digestibilidade in vitro da matéria seca (DIVMS), como mostra a Tabela 3. Os valores da composição química dos nutrientes dessa forrageira avaliados sob as condições experimentais foram semelhantes aos descritos por Santos et al. (2000), Cecato et al. (2001) e Gonçalves et al. (2001).

A composição e o consumo da dieta, associados a outros fatores como temperatura e umidade influenciam o
Tabela 3: Composição química do Coastcross em matéria seca (MS), proteína bruta (PB), fibra em detergente neutro (FDN), fibra em detergente ácido (FDA) e digestibilidade in vitro da matéria seca (DIVMS), obtida em cada período experimental

\begin{tabular}{|c|c|c|c|c|c|}
\hline \multirow[b]{2}{*}{ PERÍODO } & \multirow[b]{2}{*}{ AMOSTRAS } & \multicolumn{4}{|c|}{ PARÁMETROS ANALISADOS } \\
\hline & & PB (\%) & FDN (\%) & FDA (\%) & DIVMS \\
\hline \multirow{5}{*}{ Um } & $\mathrm{S}_{11}$ & 12,01 & 72,33 & 35,36 & 67,95 \\
\hline & $S_{12}$ & 12,29 & 71,36 & 33,28 & 66,49 \\
\hline & $\mathrm{S}_{21}$ & 12,59 & 72,18 & 37,67 & 63,76 \\
\hline & $\mathrm{S}_{22}$ & 14.13 & 71.83 & 33.06 & 65,44 \\
\hline & Média 1 & 12,75 & 71,92 & 34,84 & 65,91 \\
\hline \multirow[t]{5}{*}{ Dois } & $\mathrm{S}_{11}$ & 10,04 & 71,65 & --- & 62,49 \\
\hline & $\mathrm{S}_{12}$ & 10,14 & 74,36 & 36,49 & 60,99 \\
\hline & $S_{21}$ & 13,38 & 72,30 & 36,39 & 61,05 \\
\hline & $\mathrm{S}_{22}$ & 13,32 & 71,89 & 35,41 & 66,10 \\
\hline & Média 2 & 11,72 & 72,55 & 36,09 & 62,65 \\
\hline \multirow[t]{5}{*}{ Três } & $\mathrm{S}_{11}$ & 10,68 & 68,04 & 34,44 & 61,20 \\
\hline & $S_{12}$ & 10,75 & 67,62 & 34,58 & 61,35 \\
\hline & $\mathrm{S}_{21}$ & 9,23 & 67,18 & 38,11 & 67,55 \\
\hline & $\mathrm{S}_{22}$ & 7,73 & 70,33 & 40,63 & 61,48 \\
\hline & Média 3 & 9,59 & 68,29 & 36,94 & 62,89 \\
\hline \multirow[t]{5}{*}{ Quatro } & $\mathrm{S}_{11}$ & $\overline{16,74}$ & 67,02 & 31,21 & 66,05 \\
\hline & $S_{12}$ & 13,98 & 70,22 & 32,65 & 62,36 \\
\hline & $\mathrm{S}_{21}$ & 10,39 & 69,15 & 33,28 & 63,72 \\
\hline & $\mathrm{S}_{22}$ & 10,31 & 66,54 & 35,18 & 62,21 \\
\hline & Média 4 & 12,85 & 68,23 & 33,08 & 63,58 \\
\hline \multicolumn{2}{|c|}{ MÉDIA GERAL } & 11,72 & 70,24 & 35,23 & 63,75 \\
\hline
\end{tabular}

Fonte: Laboratório de Análise de Alimentos (LAA) da EMBRAPA - Gado de Leite, Juiz de Fora - MG.

$\mathrm{S}_{11}$ : Tratamento 1 e Repetição $1 \ldots$

Valor médio do Estrato etéreo = 1,89 \% MS. MS média $=23,77 \%$.

desempenho do animal (Barbosa et al. 2004), por isso tornase necessário avaliá-los. A Tabela 4 apresenta os valores médios de consumo de matéria seca dos nutrientes fornecidos aos animais experimentais envolvidos neste estudo.

O consumo diário esperado para vacas da raça Holandesa, em lactação com produção diária entre 15 a 20 kg de leite e com peso médio de $550 \mathrm{~kg}$, segundo o NRC (2001) é de 15,50 a 19,70 quilos de MS. Neste estudo, os animais de ambos os tratamentos consumiram uma menor quantidade de alimento, que poderia se relacionar com fatores climáticos, como a alta temperatura, observada durante o período experimental, como apresentada na Tabela 1.

O peso dos animais não foi afetado pelos tratamentos experimentais $(P>0,05)$, embora sejam observados valores numéricos diferentes (Tabela 5). Para os animais SU1 atingirem peso médio equivalente ao dos animais SU2, haveria a necessidade de ingerirem adicionalmente $1,0 \mathrm{~kg}$ de NDT/dia durante 75 dias, proporcionando a esses animais, um ganho de peso de $0,4 \mathrm{~kg} /$ dia, totalizando $75 \mathrm{~kg}$ de NDT, o que corresponderia a $87,34 \mathrm{~kg}$ do concentrado utilizado neste estudo.

O escore da condição corporal foi influenciado pelo tratamento $(\mathrm{P}<0,05)$. Os animais SU1 ingeriram $2,67 \mathrm{~kg} \mathrm{MS}$ de concentrado/dia a menos, e consumiram 1,45 kg de MS de forragem a mais, demonstrando assim o efeito substitutivo, quando comparados aos animais SU2. Mesmo ocorrendo o efeito substitutivo, os animais SU1 obtiveram menor ingestão 
Tabela 4: Consumo de matéria seca e nutrientes contidos na dieta fornecida aos animais experimentais

\begin{tabular}{|c|c|c|c|}
\hline \multicolumn{2}{|c|}{ Consumo (kg/dia) } & \multicolumn{2}{|c|}{ Grupos Experimentais } \\
\hline & & SU1 & SU2 \\
\hline \multirow[t]{5}{*}{ Volumoso (pasto) } & MS (kg) & 10,69 & 9,24 \\
\hline & PV (\%) & 2,53 & 2,61 \\
\hline & PB total (\%) & 1,253 & 1,083 \\
\hline & EE total $(\mathrm{kg})$ & 0,202 & 0,174 \\
\hline & FDN (kg) & 7,508 & 6,490 \\
\hline \multirow[t]{4}{*}{ Concentrado } & MS (kg) & 2,67 & 5,34 \\
\hline & PB total (\%) & 0,566 & 1,133 \\
\hline & EE total $(\mathrm{kg})$ & 0,147 & 0,294 \\
\hline & FDN (kg) & 1,053 & 2,106 \\
\hline \multirow[t]{8}{*}{ Dieta total } & Vol:Conc & $80: 20$ & $63: 37$ \\
\hline & MS total $(\mathrm{kg})^{*}$ & 13,36 & 14,58 \\
\hline & PB total $(\mathrm{kg})$ & 1,819 & 2,216 \\
\hline & $\%$ PB na dieta & 13,60 & 15,20 \\
\hline & EE total $(\mathrm{kg})$ & 0,349 & 0,468 \\
\hline & $\%$ EE na dieta & 2,61 & 3,20 \\
\hline & FDN (kg) & 8,561 & 8,596 \\
\hline & $\%$ FDN na dieta & 64,00 & 59,00 \\
\hline
\end{tabular}

*Valores estimados pela equação do NRC (2001).

diária de nutrientes, dentre estes $0,394 \mathrm{~kg}$ de $\mathrm{PB}$, o que possivelmente proporcionou menor deposição de tecido corpóreo, e conseqüente ECC inferior.

O NRC (2001) relata necessário aproximadamente 421 Mcal de energia metabólica (EM) para obter ganho de uma unidade no ECC, sendo necessário assim 135,89 kg do concentrado utilizado neste estudo, já que um quilo do mesmo corresponde a 3,098 Mcal.

Tabela 6: Produção de leite média de vacas holandesas submetidas a dois níveis de suplementação de concentrado (SU1 e SU2)

\begin{tabular}{lcccc}
\hline \multicolumn{1}{c}{ Produção de leite (PL) } & \multicolumn{2}{c}{ Grupo Experimental } & \multicolumn{2}{c}{ Coeficiente de } \\
& SU1 & SU2 & Variação (\%) & Significância \\
\cline { 2 - 4 } & $466,89 \pm 48,47$ & $488,27 \pm 49,72$ & 34,61 & 0,60 \\
PL total (kg/dia) & 15,56 & 16,27 & \\
PL vaca (kg/dia) & 14,39 & 14,68 & \\
PL corrigida: 4\% gordura (kg/dia) & & & \\
\hline
\end{tabular}

Wildman et al. (1982) relataram que o ECC como apresentado pelos animais neste estudo somente deveria ser observado na fase inicial de lactação, e que a partir do segundo mês de lactação o mesmo precisaria ser superior.

Vilela et al. (2004) relataram que, ao fornecer maior suplementação às vacas leiteiras, as mesmas apresentam maior ECC, e manifestam o primeiro estro pós-parto precocemente $(P<0,05)$, em média 25 dias antes daquelas não suplementadas.
Tabela 5: Valores médios, seguidos pelo desvio-padrão, do peso (PV) e escore da condição corporal (ECC) dos animais alimentados com três (SU1) e seis (SU2) quilos de concentrado por dia, durante o período experimental

\begin{tabular}{lcc}
\hline \multirow{2}{*}{ Variável } & \multicolumn{2}{c}{ Grupo experimental } \\
\cline { 2 - 3 } & SU1 & SU2 \\
\hline Peso $(\mathrm{kg})$ & $528,00 \pm 83,00^{\mathrm{a}}$ & $558,00 \pm 86,00^{\mathrm{a}}$ \\
ECC $^{*}$ & $2,61 \pm 0,04^{\mathrm{a}}$ & $2,76 \pm 0,04^{\mathrm{b}}$ \\
\hline
\end{tabular}

*Valores médios na mesma linha, seguidos por letras diferentes diferem $(P<0,05)$.

Maixner et al. (2004) relataram produção média diária de 20,70 litros de leite, em vaca da raça Holandesa, alimentadas exclusivamente em pastejo de Cynodon sp, contendo $3 \%$ de MS. Esta produção foi superior à encontrada neste estudo, talvez pela menor oferta de forrageira e maior taxa de lotação (unidade animal/ hectare).

A Tabela 6 apresenta os valores médios de produção de leite de vacas holandesas submetidas a dois níveis de suplementação de concentrado (SU1 e SU2), onde se observa que o nível de suplementação não interferiu na quantidade de leite produzida pelos animais experimentais $(P>0,05)$.

Vilela et al. (2003) relataram que vacas holandesas, mantidas em pastagens de Cynodon sp e suplementadas com silagem de milho durante o inverno, produziram 14,40 e 17,20 quilos de leite, quando receberam três e seis quilos de concentrado, respectivamente. Estes dados se aproximam daqueles obtidos neste estudo, onde os animais SU1 e SU2 produziram em média 15,46 e 16,27 litros/dia, respectivamente. Acrescenta-se ainda que os animais deste estudo encontravam-se no terço final da lactação (207 \pm 107 e $233 \pm$ 119 dias de lactação para animais SU1 e SU2, respectivamente), apresentando declínio da produção de leite, que possivelmente poderia justificar a ausência de efeito na produção dos animais do SU2, que receberam o dobro da quantidade de concentrado que foi fornecida aos animais do SU1.

A diferença na quantidade de concentrado que foi fornecida para os animais SU2 proporcionou aumento na ingestão de PB/dia em 0,397 quilo, que seria suficiente para se aumentar a produção em cinco quilos de leite contendo $4 \%$ de gordura (NR 2001). No entanto, a diferença na produção média de leite entre os animais experimentais foi 0,710 quilo. Dessa forma, é coerente supor que a maior ingestão de concentrado dos animais SU2 proporcionou redução na ingestão de volumoso, promovendo um efeito substitutivo na MS e ingredientes da dieta total. Acrescenta-se ainda que a maior quantidade de nutrientes ingerida possa ter sido utilizada para maior dissipação de calor ou termorregulação pelo organismo animal, frente às altas temperaturas observadas durante o período experimental (Tabela 1). 
Shearer e Beede (1990) relataram que durante períodos de alta temperatura, vacas de raça holandesa apresentam redução de 10 a $25 \%$ na produção de leite. Adicionalmente, Barbosa et al. (2004) destacaram a importância, para a produção eficiente de leite, do uso de ventiladores, aspersores e áreas sombreadas para auxiliar a termorregulação de vacas holandesas em lactação, que poderiam ser recomendados considerando critérios técnicos e econômicos.

Considerando ainda a diferença da produção de leite frente à quantidade de concentrado consumida, entre os animais do grupo SU2 em comparação aos do SU1, é possível que o estágio de lactação tenha influenciado na produção observada, uma vez que animais do grupo SU2 se encontravam em estágio mais adiantado de lactação, quando comparados aos animais do grupo SU1, sendo de $233 \pm 119$ e $207 \pm 107$ dias de lactação, respectivamente $(P<0,05)$.

A composição do leite não foi influenciada pela quantidade de concentrado fornecido aos animais dos grupos SU1 e SU2 $(\mathrm{P}<0,05)$, exceto para a $\mathrm{CCS} / \mathrm{mL}$ (Tabela 7$)$.

Tabela 7: Composição do leite (gordura, proteína, lactose, sólidos totais e CCS) de vacas holandesas submetidas a dois níveis de suplementação de concentrado (SU1 e SU2)

\begin{tabular}{|c|c|c|c|c|}
\hline \multirow{2}{*}{ Composição do leite } & \multicolumn{2}{|c|}{ Grupo Experimental } & \multirow{2}{*}{$\begin{array}{c}\text { Coeficiente } \\
\text { de Variação (\%) }\end{array}$} & \multirow[t]{2}{*}{ Significância } \\
\hline & SU1 & SU2 & & \\
\hline $\begin{array}{l}\text { Gordura (\%) } \\
\text { Gordura (kg/dia) }\end{array}$ & $\begin{array}{c}3,50 \pm 0,03 \\
0,544\end{array}$ & $\begin{array}{c}3,35 \pm 0,03 \\
0,545\end{array}$ & 12,52 & 0,149 \\
\hline $\begin{array}{l}\text { Proteína (\%) } \\
\text { Proteína (kg/dia) }\end{array}$ & $\begin{array}{c}2,97 \pm 0,12 \\
0,462\end{array}$ & $\begin{array}{c}3,16 \pm 0,12 \\
0,514\end{array}$ & 13,55 & 0,053 \\
\hline $\begin{array}{l}\text { Lactose (\%) } \\
\text { Lactose (kg/dia) }\end{array}$ & $\begin{array}{c}4,36 \pm 0,08 \\
0,678 \\
\end{array}$ & $\begin{array}{c}4,31 \pm 0,08 \\
0,701 \\
\end{array}$ & 5,32 & 0,35 \\
\hline $\begin{array}{l}\text { Sólidos totais }(\%) \\
\text { Sólidos totais (kg/dia) }\end{array}$ & $\begin{array}{c}11,75 \pm 0,16 \\
1,828 \\
\end{array}$ & $\begin{array}{c}11,73 \pm 0,15 \\
1,908 \\
\end{array}$ & 5,64 & 0,90 \\
\hline $\mathrm{CCS} / \mathrm{mL}\left(\times 10^{5}\right)$ & $4,45 \pm 2,37^{a}$ & $8,43 \pm 2,29^{b}$ & 106,29 & 0,02 \\
\hline
\end{tabular}

${ }^{*}$ Médias seguidas por letras diferentes dentro da mesma linha diferem.

Vilela et al. (2003) relataram que não houve variação na composição do leite de vacas mantidas em pastagem de Cynodon sp, suplementadas com silagem de milho no inverno, e com a mesma quantidade de concentrado que foi fornecida aos animais desse estudo.

Os valores médios de gordura e sólidos totais do leite dos animais deste estudo foram menores do que os descritos por Vilela e colaboradores (2003), sendo de 3,50/3,35 e 3,77/ $3,66 \%$ de gordura e $11,75 / 11,73$ e $12,08 / 12,16 \%$ de sólidos totais, para animais alimentados com três e seis quilos de concentrado, inseridos neste estudo e no estudo de Vilela et al. (2003), respectivamente.Tal fato pode ser justificado pela maior densidade energética fornecida pela silagem e a menor energia metabólica utilizada para o mecanismo de termorregulação.

Já os parâmetros de proteína e lactose do leite das vacas alimentadas com três e seis quilos de concentrado foram semelhantes àqueles descritos por Vilela et al. (2003), sendo de 2,97/3,16 e 3,01/3,20\% de proteína e 4,36/4,31 e 4,39/4,37\% de lactose, respectivamente. Fredeen (1996) e Vilela et al. (2003) relataram que a lactose é o constituinte do leite que menos sofre influência da dieta fornecida ao animal.
Os valores de proteína e gordura do leite dos animais inseridos em ambos os tratamentos se encontravam discretamente inferiores àqueles descritos na literatura. No entanto, a mesma destaca que freqüentemente vacas muito magras apresentam menor produção e menor concentração de gordura no leite (Fergusson et al., 1994). Dessa forma, é possível que o ECC dos animais experimentais tenha interferido negativamente sobre os parâmetros citados.

O Regulamento de Inspeção Industrial e Sanitária de Produtos de Origem Animal - RIISPOA (Brasil, 2002) recomenda valores superiores a $2,90 \%$ de proteína no leite de vaca. Observa-se então que a porcentagem de proteína do leite dos animais inseridos em ambos os tratamentos deste estudo atende à recomendação mencionada, sendo de 2,97 e $3,16 \%$ de proteína do leite das vacas SU1 e SU2, respectivamente.

Embora o teor de gordura do leite dos animais SU1 e SU2 não tenha apresentado diferença $(P>0,05)$, observou-se que, com o aumento da ingestão de concentrado pelos animais SU2, houve discreta tendência de decréscimo dessa variável. A diminuição da concentração da gordura no leite muitas vezes está associada ao aumento na suplementação de concentrados energéticos, e ao fornecimento de fontes de amido de rápida fermentação ruminal. Como resposta a essa alimentação, geralmente, ocorrem mudanças na proporção acetato/propionato no rúmen, levando a uma redução relativa na disponibilidade de precursores lipogênicos em relação aos glicogênicos (Agenas et al., 2002).

Bargo et al. (2003) relataram inconsistências nos dados que certificam - efeito da suplementação de gordura (gordura vegetal, animal e inerte) sobre a produção de leite de vacas em pastejo, visto que as forragens possuem maior perfil de ácidos graxos insaturados em sua composição. No presente estudo, embora a porcentagem de gordura fornecida aos animais SU2 tenha sido maior $(3,20 \%)$ daquela fornecida aos animais SU1 (2,60\%), a diferença na porcentagem de gordura ingerida pelos animais SU2 não influenciou o teor de gordura do leite desses animais $(P>0,05)$.

Embora ligeiramente inferior àquela obtida por Vilela et al. (2003), a porcentagem de gordura do leite dos animais SU1 e SU2, 3,50 e 3,35\%, respectivamente, encontra-se dentro do estabelecido pelo Artigo 476 do RIISPOA (Brasil, 2002), que preconiza um teor mínimo de $3,0 \%$ de gordura no leite de vacas.

Já os teores de sólidos totais do leite das vacas de ambos os tratamentos encontram-se semelhantes aos obtidos por Vilela et al. (2003), enquadrando-se na recomendação do RIISPOA (Brasil, 2002), que preconiza valor médio de $11,50 \%$ de sólidos totais no leite de vacas.

A CCS no leite dos animais do grupo SU2 $\left(8,432 \pm 2,29 \times 10^{5}\right.$ células $/ \mathrm{mL}$ de leite) foi maior que a encontrada nos animais SU1 $\left(4,459 \pm 2,37 \times 10^{5}\right.$ células $/ \mathrm{mL}$ de leite $)(P<0,05)$. Em ambos os grupos o leite produzido pelos animais 
experimentais apresentou CCS acima do nível máximo recomendado que é de $3,0 \times 10^{5}$ células $/ \mathrm{mL}$ de leite (Brito e Brito, 1998). No entanto, o mesmo atende às exigências apresentadas pela Normativa 51 , que preconiza $10,0 \times 10^{5}$ células/mL de leite (Brasil, 2002).

Apesar das citações, o Brasil ainda não dispõe de norma regulamentar oficial para a CCS no leite. O que existe são iniciativas de empresas privadas em programas de incentivo à qualidade do leite, que ficam restritas ao universo de seus fornecedores. Essa situação poderá se modificar em função das novas Normas de Lácteos, prevista inicialmente para o ano de 2001, e que foi postergada para 2006 (Brasil, 2002). Neste caso, o Regulamento Técnico de Produção, Identidade e Qualidade dos Leites tipo "A e B" determina que o máximo na CCS seja de $6,0 \times 10^{5}$ células $/ \mathrm{mL}$ de leite, enquanto que o Regulamento Técnico de Identidade e Qualidade do Leite Cru Refrigerado amplia esse limite para $10,0 \times 10^{5}$ células $/ \mathrm{mL}$ de leite. Considerando esses valores, o leite produzido neste estudo, cuja CCS variou de 4,45 $\pm 2,37$ a 8,43 $\pm 2,29$ células/

\section{Referências}

AGENAS, S.; HOLTENIOUS, K.; GRIINARI, M.;BURSTEDT, E. Effects of turnout to pasture and dietary fat supplementation on milk fat composition and conjugated linoleic acid in dariy cows. Acta Agricultural Scandinavian, v. 52, p. 25-33, 2002.

BARBOSA, O.R.; BOZA, P.R.; SANTOS, G.T. et al. Efeitos da sombra e da aspersão de água na produção de leite de vacas da raça Holandesa durante o verão. Acta Scietiarum, v. 26, n 1, p. 115-122, 2004.

BARGO, F.; MULLER, L.D.; KOLVER, E.S. et al. Invited Review: Production and digestion of supplemented dairy cows on pasture. Journal of Dairy Science, v. 86, p. 1-42, 2003.

BRASIL, Ministério da Agricultura, Pecuária e Abastecimento. Instrução Normativa $n^{\circ} 51$. Regulamentos técnicos de produção, identidade, qualidade, coleta e transporte de leite. Brasília, DF, 2002. 24 p.

BRITO, J. R. F.; BRITO, M. A. V. P. A qualidade do leite. Embrapa. Tortuga, 1998, p. 46-50.

CECATO, U.; SANTOS, G.T.; MACHADO, M.A. et al. Avaliação de cultivares do gêner Cynodon com e sem nitrogênio. Acta Scientiarum, v. 23, n. 4, p. 781-788, 2001.

EDMONSON, A.J.; LEAN, I.J.; WEAVER, L.D. et al. Abody scoring chat for Holsteins dairy cows. Journal of Dairy Science, v. 72, p. 68, 1989.

FERGUSSON, J.D. et al. Roundtable discussion: body condition of lactiation cows. Agri-Practice, v.15, p.17-21, 1994.

FREDEEN, A.H. Considerations in the nutritional modification of milk composition. Animal Feed Science and Technology, v. 59, n. 1-3, p.185-197, 1996.

GONÇALVES, G.D.; SANTOS, G.T.; CECATO, U. et al. Produção e valor nutritivo de gramíneas do gênero Cynodon em diferentes idades ao corte durante o ano. Acta Scientiarum, v. 24, n. 4, p. 1163-1174, 2001. GUSTAFSSON, A.H. y PALMQUIST, D. L. Diurnal variation of rumen ammonia, serum urea and milk urea in dairy cows at high and low yields. J. Dairy Sci, v. 76, p. 475-484, 1993.

MAIXNER, A. R; KOZLOSKI, G. V.; QUADROS, F. L. F.;TREVISAN, L.M.; MONTARDO, D.P.; NORONHA, A; AURÉLIO, N.D. Avaliação de tifton 85 ("cynodon" sp. cv. tifton 85) e de capim-elefante anão ("pennisetum purpureum" cv. mott ) em sistemas de produção de leite a pasto: consumo de forragem e produção individual de leite. REUNIÃO ANUAL DA SOCIEDADE BRASILEIRA DE ZOOTECNIA, 2004. Campo Grande CG. Campo Grande. Anais... : SBZ, 2004. CD-ROM.
$\mathrm{mL}$ satisfaz às exigências apresentadas, indicando que o leite possui qualidade aceitável para o consumo.

Embora o leite produzido pelos animais experimentais em ambos tratamentos não tenha sofrido alterações em sua composição, cujos valores encontram-se dentro dos preconizados pela legislação (Brasil, 2002), os mesmos são relativamente baixos e, por isso, a sua comercialização não é capaz de oferecer vantagens econômicas, uma vez que o seu valor é baseado nos teores de seus constituintes.

\section{Conclusão}

Nas condições deste estudo, a suplementação de vacas holandesas no terço final de lactação mantidas em pastejo de Coastcross sp, com três e seis quilos de concentrado, não influenciou o peso corporal, a produção e a composição do leite (gordura, proteína, lactose e sólidos totais). No entanto, a suplementação influenciou o ECC e a CCS.

NRC - National Research Council - Nutrient Requirements of Dairy Cattle. 7th ed. Washington: Natl. Academic Science., 2001. 408 p.

REIS, R.B.; ANTUNES, R.C. Alimentação de vacas de alta produção. In: SIMPÓSIO MINEIRODE NUTRIÇÃO DE GADO DE LEITE, 2., 1999, Belo Horizonte. Anais... Belo Horizonte: Escola de Veterinária-UFMG, 1999. p. 99-115.

SANTOS, G.T.; MACHADO, M.A; GONÇALVES, G.D. etal. Determinação da digestibilidade in vitro de gramíneas do gênero Cynodon com uso de diferentes metodologias. Acta Scientiarum, v. 22, n. 3, p.761-764, 2000.

STATISTICAL ANALYSIS SYSTEMS INSTITUTE (SAS). Statistical analysis systems user's guide: stat, version 6.11. Cary, NC: SAS Institute, 1996.

SHEARER, J.K.; BEEDE, D.K. Thermoregulation and physiological response of dairy cattle in hot weather. Agriculture-Practice, v. 11, n. 4, p.5-18, 1990.

TEIXEIRA, N.M.; FREITAS, A.F.; BARRA, R.B. Influência de fatores de meio ambiente na variação mensal da composição e contagem de células somáticas do leite em rebanhos do Estado de Minas Gerais. Arquivo Brasileiro de Medicina Veterinária e Zootecnia, v. 55, n. 4, 2003. Disponível em: www.abmvz.ufmg.br. Acesso: 13/agosto/2005.

VILELA, D. et al. Efeito da suplementação concentrada na quantidade, qualidade e economia do leite produzido por vacas Holandesas em pastagem de Cynodon. In: REUNIÃO ANUAL DA SOCIEDADE BRASILEIRA DE ZOOTECNIA, 40. 2003. Santa Maria-RS. Anais... Santa Maria: SBZ, 2003. CD-ROM.

VILELA, D. et al. Efeito da suplementação concentrada no intervalo parto-primeiro cio detectado pelos métodos visual e da dosagem de progesterona em vacas holandesas manejadas em pastagem de cynodon em lotação rotacionada. REUNIÃO ANUAL DA SOCIEDADE BRASILEIRA DE ZOOTECNIA, 40., 2004. Campo Grande-MS. Anais... Santa Maria: SBZ, 2004. CD-ROM.

WILDMAN, E.E. et al. A dairy cow body condition scoring system and its relationship to select production characteristics. Journal of Dairy Science, v. 65, p. 495-501, 1982. 